\title{
ATRIBUTOS FÍSICOS E QUÍMICOS DE SOLO CULTIVADO COM CANA-DE-AÇÚCAR PRÓXIMO A FRAGMENTO NATIVO
}

\section{PHYSICAL AND CHEMICAL ATTRIBUTES OF SOIL CULTIVATED WITH SUGAR CANE FRAGMENT NEAR NATIVE}

\section{Ludmila de Freitas ${ }^{1}(\mathrm{PG})$, José Carlos Casagrande ${ }^{2}$ (PQ), Ivan César Desuó ${ }^{3}$ (PG),}

\author{
${ }^{1}$ Bióloga. Instituto de Biociências, Universidade Estadual Paulista, UNESP \\ ludmilafreitas@hotmail.com \\ ${ }^{2}$ Engenheiro Agrônomo. Prof. Dr. Centro de Ciências Agrárias - CCA- Universidade \\ Federal de São Carlos - UFSCAR bighouse@cca.ufscar.br \\ ${ }^{3}$ Biólogo.Instituto de Biociências, Universidade Estadual Paulista - UNESP, \\ ivandesuo@yahoo.com.br
}

\begin{abstract}
RESUMO
Atualmente, o meio rural é dominado pelas grandes áreas intensamente cultivadas com monoculturas, solo descoberto sofrendo intenso processo erosivo, zonas ripárias sem vegetação, e pequenos fragmentos florestais isolados e perturbados pelas atividades humanas. Esse modelo mostra-se hoje insustentável, com conseqüências ambientais graves e irreversíveis. Este trabalho teve como objetivo caracterizar parâmetros físicos e químicos com a finalidade de explicar a influência de fragmentos florestais nativos sobre a produção e qualidade da cana-de-açúcar cultivada próximo aos fragmentos e, também, comprovar a utilidade da conservação desses fragmentos. O estudo foi realizado em um fragmento no Centro de Ciências Agrárias - Campus de Araras da UFSCar, Estado de São Paulo. Para atingir este objetivo, foi avaliada a qualidade do solo, através de seus componentes: matéria orgânica, $\mathrm{pH}, \mathrm{P}, \mathrm{K}, \mathrm{Ca}, \mathrm{Mg}, \mathrm{S}, \mathrm{Al}, \mathrm{H}+\mathrm{Al}, \mathrm{Na}, \mathrm{B}, \mathrm{Fe}, \mathrm{Mn}, \mathrm{Zn}$, m, SB, CTC, V, densidade, macro e microporosidade, em intervalos de $5 \mathrm{~m}$ até a distância de $50 \mathrm{~m}$ da borda florestal em direção à área agrícola, adentrando a área cultivada com cana e $10 \mathrm{~m}$ no interior da mata, sendo a amostragem do solo feita nas profundidades de 0-10 e 10-20 cm. As matrizes de mata e de cana-de-açúcar se mostraram muito diferentes em relação às características do solo. Os efeitos observados no solo cultivado com cana-de-açúcar foram mais nítidos e acentuados nos primeiros 20 metros de distância da mata.
\end{abstract}

Palavras chave: Fragmentos florestais nativos. Monocultura de cana-de-açúcar.

\footnotetext{
ABSTRACT

Currently, the countryside is dominated by intensively cultivated areas with large monocultures, bare ground suffering severe erosion, riparian areas without vegetation and small forest fragments isolated and disturbed by human activities. This model proves to be untenable today, with severe
} 
and irreversible environmental consequences. This study aimed to characterize physical and chemical parameters in order to explain the influence of native forest fragments on production and quality of sugar cane grown near the fragments and also prove the usefulness of conservation of these fragments. The study was conducted in a fragment at the Center for Agricultural Sciences UFSCar Campus Araras, São Paulo. To achieve this goal, we evaluated the quality of the soil, through its components: organic matter, $\mathrm{pH}, \mathrm{P}, \mathrm{K}, \mathrm{Ca}, \mathrm{Mg}, \mathrm{S}, \mathrm{Al}, \mathrm{H}+\mathrm{Al}, \mathrm{Na}, \mathrm{B}, \mathrm{Fe}, \mathrm{Mn}, \mathrm{Zn}, \mathrm{m}, \mathrm{SB}$, CEC, $\mathrm{V}$, density, macro and microporosity, at intervals of $5 \mathrm{~m}$ to $50 \mathrm{~m}$ away from the forest edge towards the agricultural area, moving into the area cultivated with sugar cane and $10 \mathrm{~m}$ inside the forest, and soil sampling done in depths of $0-10$ and $10-20 \mathrm{~cm}$. The headquarters of forest and cane sugar were very different in relation to soil characteristics. The effects observed in soil cultivated with sugar cane were sharper and more pronounced in the first 20 meters from the forest.

Keywords: Native forest fragments. Monoculture of sugar cane.

\section{INTRODUÇÃO}

No Brasil, o cultivo da cana-de-açúcar destaca-se como uma das mais antigas atividades agroeconômicas, sendo as produções de açúcar e álcool as principais finalidades de sua exploração. Atualmente, é considerada a cultura com o maior percentual de crescimento de área cultivada e com perspectivas de maior crescimento nas próximas safras (ANDREOLI; SOUZA; 2006) devido à demanda mundial por combustíveis ambientalmente corretos.

Do ponto de vista econômico, energético, ambiental a cana-de-açúcar é a melhor alternativa para a produção de etanol no Brasil. Na safra de 2005/06, as lavouras canavieiras ocuparam quase seis milhões de hectares, com estimativa de duplicação da área plantada até o ano de 2030 (MAGALHÃES, 2005).

As vantagens da presença de floresta em áreas agrícolas são raramente discutidas, como, por exemplo, qual é o potencial que a floresta possui de fertilizar o solo ao seu redor.

As florestas proporcionam grandes benefícios ao solo, uma vez que reduzem a compactação e a erosão, mediante a atenuação progressiva do impacto da chuva, em virtude da existência de vários extratos na vegetação e da manta orgânica formada sobre o solo.

Áreas ocupadas com vegetação nativa estão cada vez mais fragmentadas devido à ocupação agrícola e antrópica, sendo que, o uso do solo na agricultura após a retirada da vegetação natural, tem freqüentemente mostrado alterações em suas propriedades químicas e biológicas, as quais são dependentes das condições do solo, do clima, do tipo de cultura e das práticas culturais adotadas (MARCHIORI JUNIOR; MELO, 2000).

Neste contexto, há a possibilidade de viabilizar o plantio de espécies florestais, em aléias, por exemplo, junto ao cultivo de cana, sendo importante ressaltar, que o Estado de São Paulo tem cerca de 4,5 milhões de ha de cana-de-açúcar e que, portanto, a quantidade de árvores que poderia ser plantada, nesse sistema, seria significativa, com impacto positivo no balanço de $\mathrm{CO}_{2}$, na paisagem e conseqüentemente na biodiversidade. Especialistas afirmam que a maneira mais eficiente de se diminuir o efeito estufa ainda é através do plantio de árvores, visto que esses seqüestram o carbono em sua biomassa. Além disso, há várias vantagens de se aliar o plantio de culturas com árvores, entre os quais se destacam o efeito das condições climáticas, condições do solo (aumento da matéria orgânica e conseqüentemente CTC, além de aumentar a umidade do solo) e componentes biológicos do solo.

A magnitude do efeito positivo dos fragmentos florestais sobre o solo cultivado com canade-açúcar poderá ser verificada pela comparação dos pontos de amostragens mais próximos e mais distantes dos respectivos fragmentos. Será elaborado um gradiente para cada parâmetro a cada $5 \mathrm{~m}$ em uma distância de $50 \mathrm{~m}$. O solo do fragmento florestal será a referência dos parâmetros mais 
adequados, enquanto na maior distância deverá, possivelmente, ocorrer os níveis mais baixos ou mais alterados.

Este trabalho teve como principal objetivo caracterizar os parâmetros físicos e químicos do solo, comprovar a utilidade da conservação das florestas nativas junto ao cultivo de cana de açúcar e indicar a utilidade do plantio de florestas em áreas de cana.

\section{MATERIAL E MÉTODOS}

\section{Área de estudo}

A área está localizada no Centro de Ciências Agrárias da Universidade Federal de São Carlos, no Município de Araras - São Paulo, localizada sob as coordenadas geográficas $22^{\circ} 18^{\prime} 31^{\prime \prime S}$ e $47^{\circ} 23^{\prime} 13^{\prime}$ 'O. (Figura 1). As duas situações escolhidas estão em uma área de solos homogêneos, classificado como Latossolo Roxo Eutrófico, contendo cerca de $50 \%$ de argila, na qual a mata e a cultura da cana-de-açúcar são adjacentes, separadas por um carreador, sendo cultivada há aproximadamente 60 anos. A classificação climática segundo Köeppen é do tipo CWA, ou seja, clima mesotérmico de inverno seco, em que a temperatura média do mês mais quente é superior a $22{ }^{\circ} \mathrm{C}$ e a do mês mais frio inferior a $18^{\circ} \mathrm{C}$. A precipitação média anual varia de $1.100 \mathrm{~mm}$ a 1.700 $\mathrm{mm}$. A média anual da umidade relativa do ar é de aproximadamente $71 \%$, ocorrendo concentração de chuvas no período de outubro a março e o período mais seco estende-se de abril até setembro. A topografia das áreas é plana, com pequena declividade.

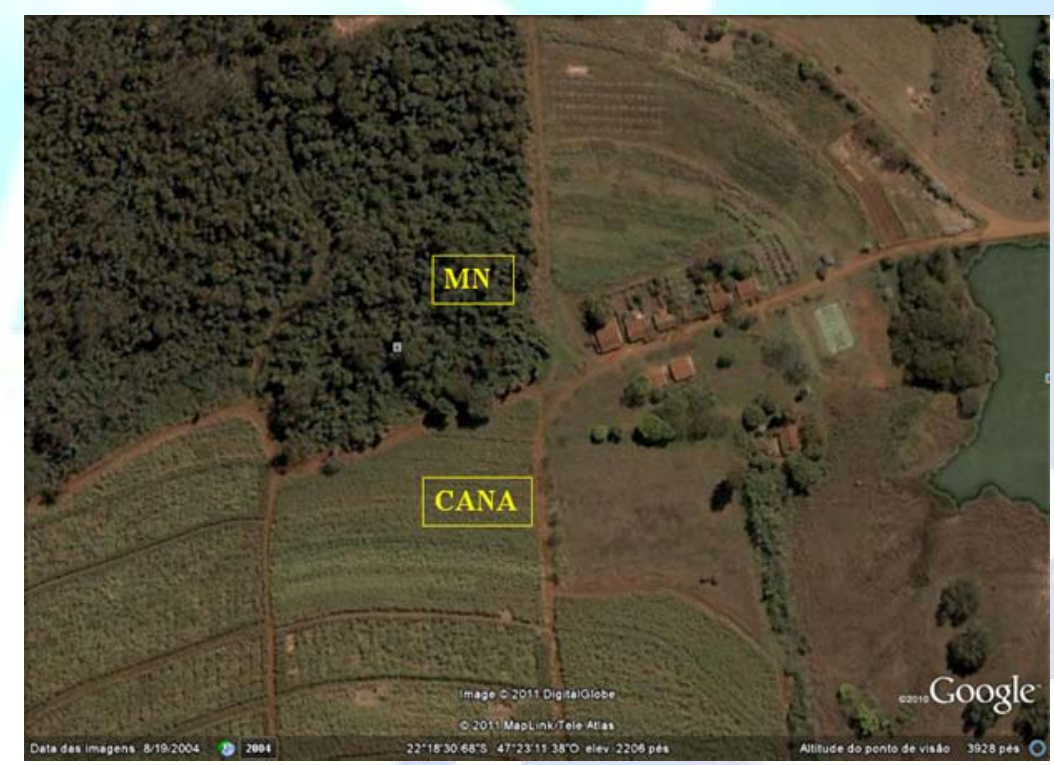

Figura 1. Localização das coletas do local da Área 1, mata nativa (MN) e cana-de-açúcar (CANA). Fonte: Google Earth, 2011.

A área cultivada com cana-de-açúcar possui aproximadamente 4 ha e a mata natural, razoavelmente conservada, representa cerca de 10 ha e se constitui em floresta Estacional (Figura 2). É cana-de-açúcar de segundo corte, sendo a RB92-5345 a variedade plantada. 

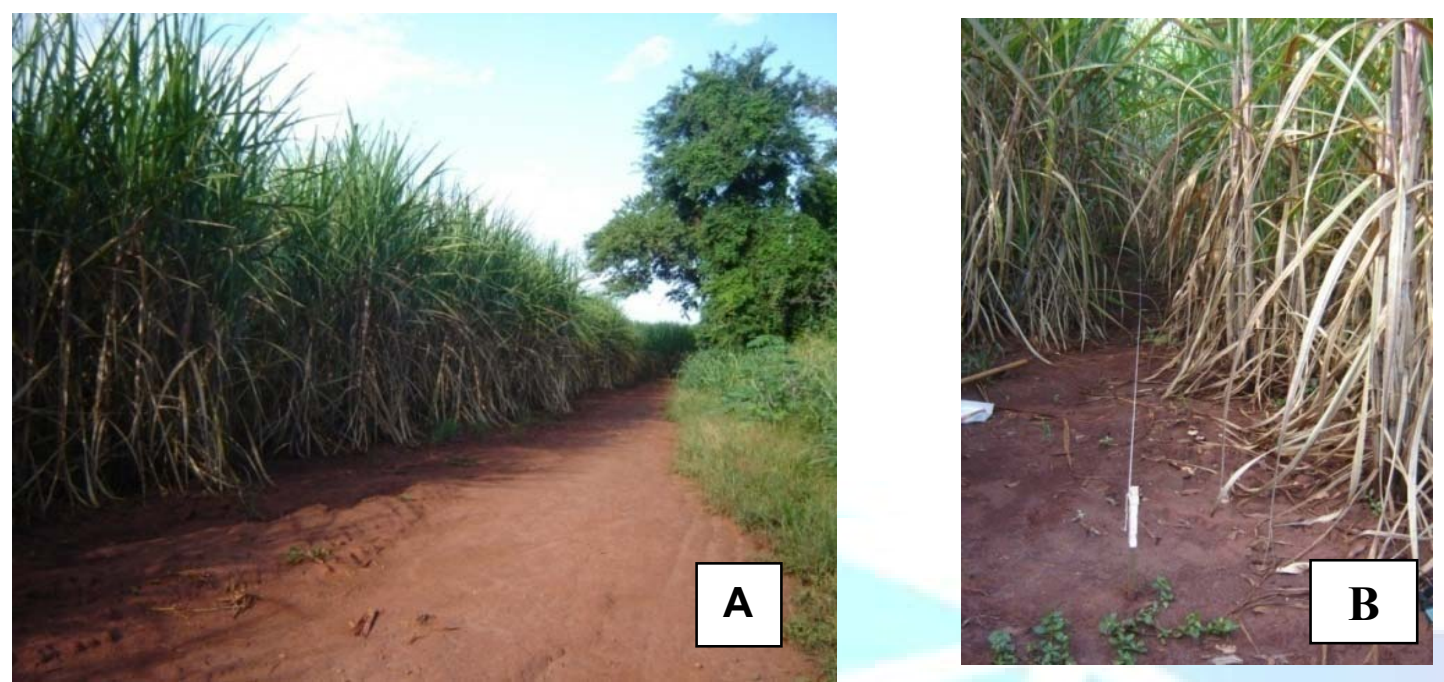

Figura 2. Representação das condições estudadas na Área 1. A) Área de mata e cana adjacentes. B) Área de amostragem: entrelinha da cana-de-açúcar.

\section{Coleta de amostras}

Foram analisados parâmetros químicos e físicos do solo, uma vez que as coletas foram realizadas em uma única época do ano para todas as análises.

Foram feitas 4 repetições em cada área estudada (L1, L2, L3 e L4) nos dois ambientes, e a cada 5m coletou-se uma amostra (P1 a P11 na cana e P0 na mata, visto que neste ambiente os pontos não diferiram estatisticamente, assim tem-se um valor médio para cada linha. $\mathrm{O}$ solo foi coletado na profundidade de $0-10$ e 10-20 cm por meio de mini trincheiras na borda da floresta e a cada $5 \mathrm{~m}$, até $50 \mathrm{~m}$ de distância, adentrando a área cultivada com cana, e $10 \mathrm{~m}$ no interior da mata. $\mathrm{Na}$ floresta, a cada $5 \mathrm{~m}$, foram coletadas quatro sub-amostras para compor uma amostra (Figura 3). As amostras foram levadas ao Laboratório de Química e Fertilidade do Solo para a realização de análise química de rotina, ao Laboratório de Física do Solo para as análises físicas, e para as análises microbiológicas para o Laboratório de Microbiologia. Estas análises foram realizadas nos laboratórios pertencentes ao Centro de Ciências Agrárias, da Universidade Federal de São Carlos, Campus de Araras, estado de São Paulo.

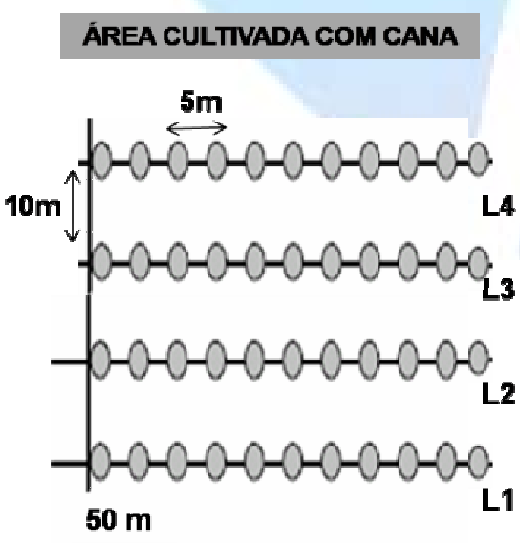

\section{FRAGMENTO DE MATA}

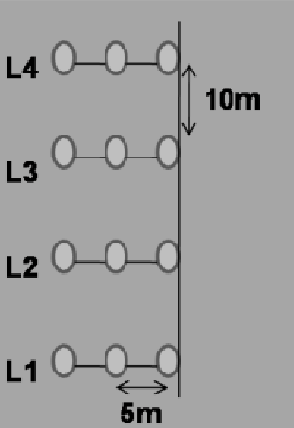

CARREADOR

Figura 3. Modelo para amostragem do solo para análises químicas e físicas do solo. 


\section{Análise física do solo}

Foram realizadas análises físicas: macro e microporosidade, densidade do solo e densidade das partículas do solo e das amostras para cada profundidade. Para essas determinações, foram coletadas amostras indeformadas com anéis volumétricos de $0,03 \mathrm{~m}$ de altura e $0,05 \mathrm{~m}$ de diâmetro, seguindo a metodologia descrita pela EMBRAPA (1997).

\section{Análise química do solo}

Para cada amostra de solo foram feitas análises químicas (Figura 3): $\mathrm{pH}$, matéria orgânica (M.O), $\mathrm{P}$ (fósforo), $\mathrm{K}$ (potássio), $\mathrm{Ca}$ (cálcio), $\mathrm{Mg}$ (magnésio), $\mathrm{S}$ (enxofre), $\mathrm{Al}$ (alumínio), $\mathrm{H}+\mathrm{Al}, \mathrm{Na}$ (sódio), B (boro), Fe (ferro), Mn (manganês), Zn (zinco), m (saturação por alumínio), SB (soma de bases), CTC (capacidade total de trocas de cátions) e V (saturação por bases), segundo metodologia da EMBRAPA (1997).

\section{Forma de Análise dos Resultados}

As análises estatísticas foram realizadas utilizando o software SAS $9.2^{\circ}$. Os resultados foram submetidos à análise fatorial multivariada e foi construído um Biplot Interativo utilizando-se o método de Componentes Principais (PCA), como forma de visualizar a existência de algum padrão entre os pontos analisados. O efeito da distância do fragmento de mata sobre a composição do solo cultivado com cana-de-açúcar foi medido através das distâncias generalizadas de Mahalanobis, calculadas a partir da análise das variáveis canônicas. Tais distâncias são multivariadas e de fácil interpretação: pequenos valores de $\mathrm{D}^{2}$ entre dois pontos significam que estes pontos são similares entre si, considerando as 22 variáveis conjuntamente; valores grandes de $\mathrm{D}^{2}$ significam que dois pontos apresentam composições de solos distintas.

\section{RESULTADOS E DISCUSSÕES}

Conforme o pressuposto de haver efeito positivo dos fragmentos florestais sobre o solo cultivado com cana-de-açúcar, esperava-se encontrar gradientes nas condições físicas e químicas do solo, em relação ao distanciamento da mata nativa para a área adjacente de cana, para o seu interior, seguindo as distâncias amostradas $(0,5$ e $10 \mathrm{~m}$ da mata e $0,5,10,15,20,25,30,35,40,45,50 \mathrm{~m}$ da cana). Além desse pressuposto, devemos levar em conta que as variáveis ambientais não sofrem variações isoladamente, ao invés disso, variam de forma conjunta, chegando muitas vezes a apresentar padrões de variações semelhantes.

A análise de correlação das áreas de cana e mata revelou a existência de um significativo gradiente positivo entre as distâncias da mata para o interior da área cultivada com cana, considerando a mata como o referencial (ponto zero) para as análises. Analisando a Figura 1 podemos observar que na borda da cana (distância $0 \mathrm{~m}$ ) houve uma diferença de ambiente de 451,39 comparando com a mata; na distância de $5 \mathrm{~m}$, uma diferença de 474,7; em 10m, 503,18; em

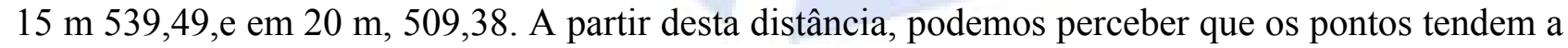
não ser mais tão significativos. Podemos afirmar que quanto menor for à distância, menor será a diferença entre os dois ambientes estudados. Assim, há uma propensão, nos primeiros 20 metros da borda para o interior da cana, de melhor qualidade do solo nesta área, com toda a probabilidade de ser resultado do efeito da presença da mata sobre os parâmetros químicos e físicos do solo estudados.

Além disso, foi possível verificar na Figura 3 que apesar da relação entre os ambientes variar com a distância, houve uma clara distinção entre o ambiente de vegetação nativa e o cultivado. Essa separação tem a mata como referência para a análise dos parâmetros químicos e 
físicos, considerada como o marco zero. A distância mais próxima, isto é, a que mais se assemelhou com a mata, é de 451,39, ou seja, uma diferença muito significativa.

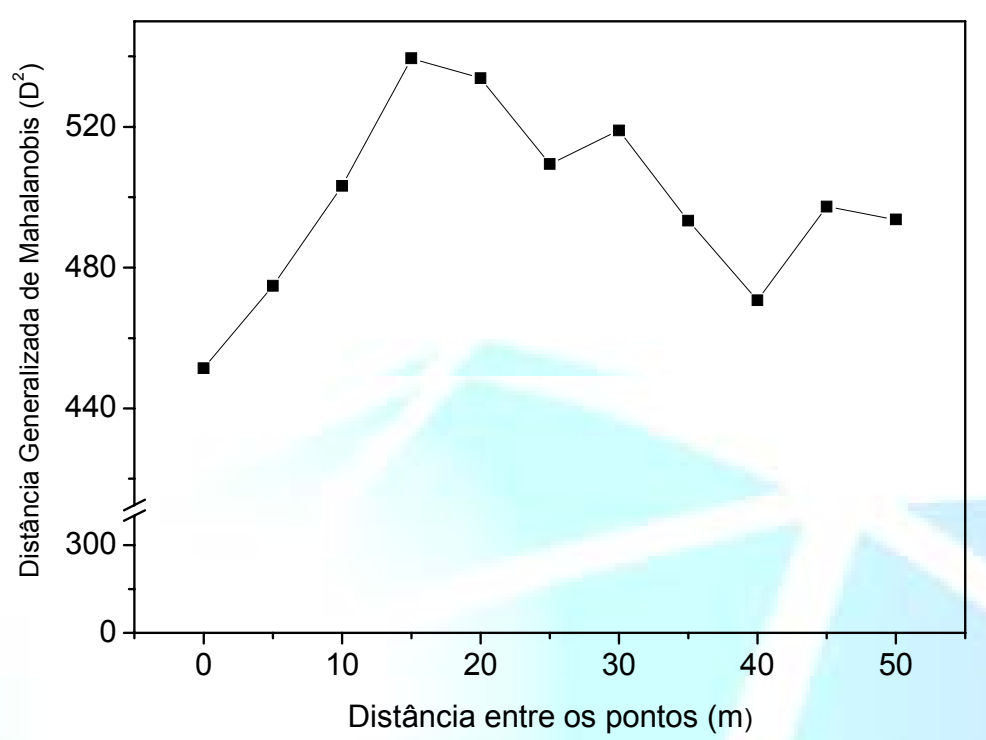

Figura 4. Distâncias generalizadas de Mahalanobis e respectivos valores de P para comparação entre os pontos amostrados.

Os dados obtidos nos pontos da área de cana-de-açúcar deferiram pouco entre si, medido pela distância generalizada (Figura 4): a maior diferença foi de $17 \%$, indicando pequena variação dos dados na linha de 50m. No entanto, considerando a mata como distância generalizada "zero", o ponto de menor distância da cana-de-açúcar foi de 451,39 e o de maior de 539,49, demonstrando grande diferença estatística.

Como se trata de uma área cultivada, não se pode esquecer que a avaliação do solo representa o momento da coleta da amostra, podendo sofrer variações ao longo do ciclo da cultura da cana-de-açúcar em função do manejo cultural empregado (aplicação de fertilizantes e colheita, principalmente).

Foi realizada a Análise de Componentes Principais (PCA), e nesta etapa buscou-se avaliar qualitativamente as características de cada área nos dois ambientes e verificar as variáveis que mais estão relacionadas com a mata e com a cana-de-açúcar. Para isso, foram extraídos três componentes principais e correlacionados os pontos da mata com os da área agrícola cultivada com cana-deaçúcar, com as vinte e duas variáveis analisadas. Os demais componentes, pouco contribuíram, não sendo considerados na análise, conforme Tabela 1. 
Tabela 1 - Valores resultantes das Análises de Componentes Principais (PCA), evidenciando o peso de cada variável das componentes.

\begin{tabular}{cccc}
\hline \hline Componente & Autovalores & $\begin{array}{c}\text { \% dos } \\
\text { Autovalores }\end{array}$ & $\begin{array}{c}\text { \% Cumulativas dos } \\
\text { Autovalores }\end{array}$ \\
\hline \hline 1 & 15,56595151 & 71 & 71 \\
2 & 2,962019992 & 13 & 84 \\
3 & 1,490211798 & 7 & 91 \\
\hline \hline
\end{tabular}

A primeira componente principal foi representada pelos autovalores positivos de M.O, $\mathrm{pH}$, $\mathrm{K}, \mathrm{Ca}, \mathrm{Mg}, \mathrm{H}+\mathrm{Al}, \mathrm{SB}, \mathrm{CTC}, \mathrm{V}, \mathrm{S}, \mathrm{B}, \mathrm{Mn}, \mathrm{Zn}$, densidade, porosidade e microporosidade, as quais praticamente separaram o fragmento mata no primeiro quadrante e a cana localizada principalmente no segundo e no terceiro quadrante, em função da maior influência dessas variáveis (Tabela 2) sob o ambiente. Entre os atributos que se correlacionaram com valores negativos tem-se somente o Al. Esses resultados demonstram a dinâmica natural do solo, onde o conteúdo dos cátions nutrientes está relacionado com a CTC e com o conteúdo de M.O.

Tabela 2 - Correlação entre variáveis originais e componentes principais dos atributos químicos e físicos do solo da Área 1 evidenciando o peso de cada variável.

\begin{tabular}{|c|c|c|c|}
\hline Peso das Variáveis & PC1 & PC2 & PC3 \\
\hline$P$ resina & 0,07 & $-0,12$ & $0,64 *$ \\
\hline М.O. & $0,24^{*}$ & 0,10 & 0,12 \\
\hline pH & $0,23 *$ & $-0,24^{*}$ & $-0,05$ \\
\hline K & $0,24^{*}$ & 0,09 & $-0,07$ \\
\hline $\mathbf{C a}$ & $0,25^{*}$ & 0,00 & 0,06 \\
\hline Mg & $0,22 *$ & $-0,18^{*}$ & $0,25^{*}$ \\
\hline $\mathbf{H}+\mathbf{A l}$ & $0,20 *$ & $0,32 *$ & 0,13 \\
\hline Al & $-0,16$ & $0,41 *$ & 0,17 \\
\hline SB & $0,25^{*}$ & $-0,02$ & 0,08 \\
\hline СТC & $0,23 *$ & $0,20 *$ & $0,21 *$ \\
\hline $\mathbf{V}$ & $0,24^{*}$ & $-0,17 *$ & $-0,04$ \\
\hline $\mathbf{S}$ & $0,22 *$ & 0,19 & 0,03 \\
\hline B & $0,24^{*}$ & 0,06 & 0,18 \\
\hline $\mathbf{C u}$ & 0,20 & 0,02 & $-0,03$ \\
\hline $\mathbf{F e}$ & 0,05 & $0,51 *$ & $-0,06$ \\
\hline Mn & $0,25^{*}$ & 0,08 & $-0,04$ \\
\hline $\mathbf{Z n}$ & $0,22 *$ & 0,17 & $0,21 *$ \\
\hline $\mathbf{m} \%$ & 0,19 & $0,36^{*}$ & 0,15 \\
\hline Densidade & $0,23 *$ & $-0,14$ & $0,22 *$ \\
\hline Porosidade & $0,22 *$ & 0,14 & $-0,22 *$ \\
\hline Microporosidade & $0,23 *$ & 0,13 & $-0,03$ \\
\hline Macroporosidade & 0,16 & 0,13 & $-0,45$ \\
\hline
\end{tabular}

* caracterização principal dos componentes principais 
Na segunda componente principal observa-se que os conteúdos de $\mathrm{H}+\mathrm{Al}, \mathrm{Al}, \mathrm{CTC}, \mathrm{Fe}, \mathrm{m} \%$, formam um grupo de características altamente correlacionadas entre si e negativamente com $\mathrm{Mg}$, $\mathrm{pH}$ e $\mathrm{V}$ que formam um outro grupo. À medida que o $\mathrm{pH}$ e a quantidade de $\mathrm{Mg}$ diminui a acidez aumenta e, conseqüentemente, existe maior quantidade de $\mathrm{H}$ livre na solução do solo, o que caracteriza uma acidez elevada.

A PCA das variáveis mostrou que levando em conta todos os aspectos químicos e físicos analisados houve uma clara distinção entre os ambientes, como pode ser visualizada na Figura 5, onde todos os pontos da mata são encontrados no primeiro quadrante e os pontos da cana nos demais quadrantes. Além disso, podemos observar que houve uma separação entre os pontos da cana, na qual, salvo algumas exceções, os pontos cujas distâncias são menores em relação à mata adjacente possuem características mais próximas das variáveis que caracterizam o ambiente mata. Assim, podemos afirmar que quanto menor for à distância, menor será a diferença entre os dois ambientes estudados.

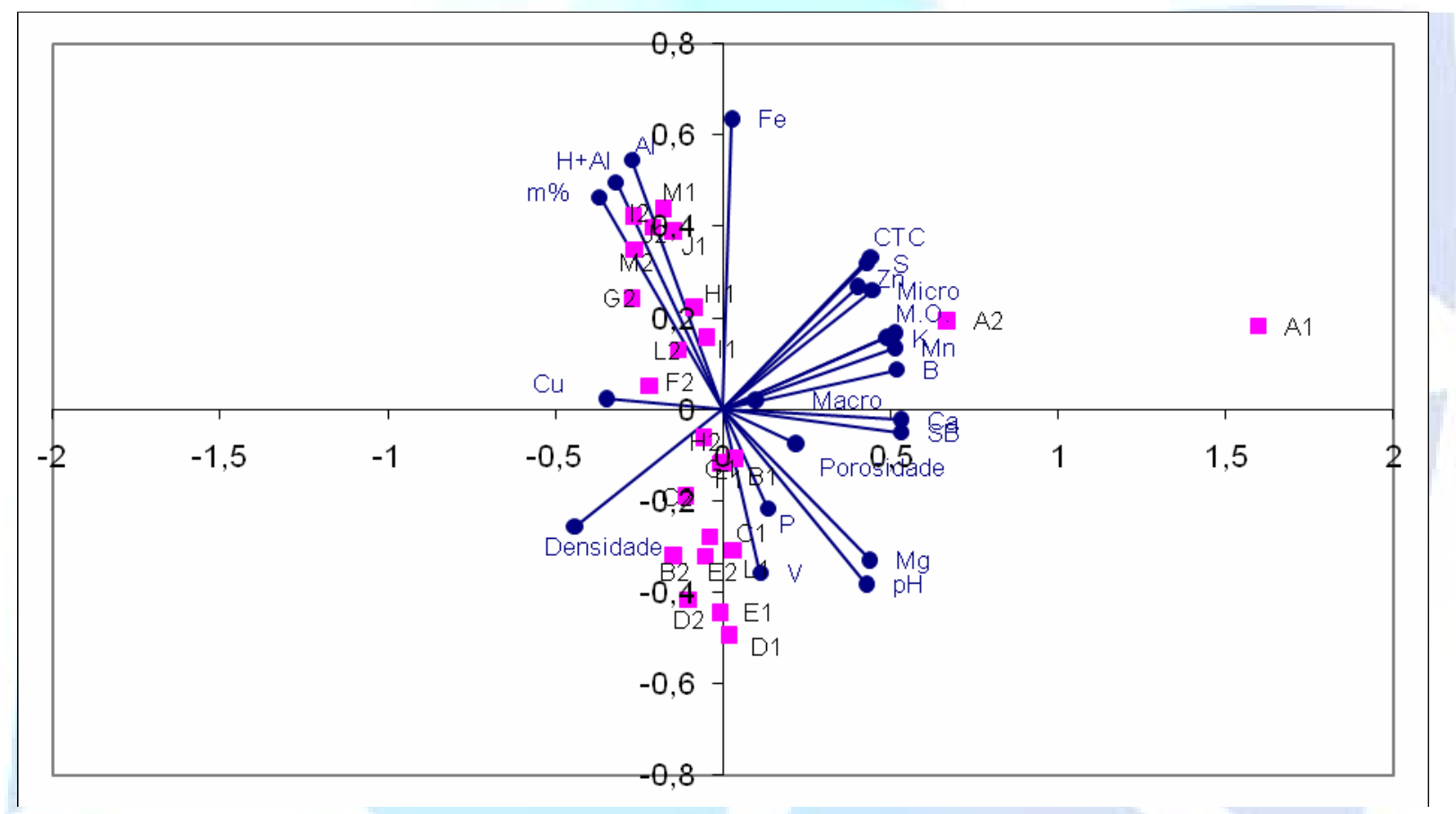

Figura 5. Análise dos componentes principais 1 e 2 das médias das variáveis comparando a área de cana-deaçúcar com mata.

$\mathrm{A} 1=$ ambiente mata na profundidade $0-10 \mathrm{~cm}$. A2= ambiente mata na profundidade $10-20 \mathrm{~cm}$.

B1 a M1 = ambiente cana nas distâncias de 0 a $50 \mathrm{~m}$ na profundidade $0-10 \mathrm{~cm}$. B2 a M2 = ambiente cana nas distâncias de 0 a $50 \mathrm{~m}$ na profundidade $10-20 \mathrm{~cm}$.

Essa separação dos pontos da mata com a área cultivada com cana salienta o fato de que o cultivo de cana-de-açúcar deve produzir uma modificação acentuada no solo, fazendo com que o mesmo se torne diferente do solo originalmente coberto por floresta. As diferenças são devidas às variações de fertilidade natural e melhores condições físicas do solo da mata e aquelas decorrentes de diferentes níveis de adubação da cana. A variação dos atributos do solo na vegetação nativa é muito menor quando se compara com solos de usos agrícolas, e por isso a vegetação nativa é um referencial para avaliação de solos incorporados a sistemas agrícolas. Nesta comparação, podem-se observar as alterações de atributos do solo após a utilização agrícola, verificando, assim, maior sustentabilidade da mata. 
Conforme a Figura 5, os pontos pertencentes ao ambiente mata encontram-se mais relacionados à $\mathrm{M} . \mathrm{O}, \mathrm{SB}, \mathrm{CTC}, \mathrm{V}, \mathrm{m} \%$ em menor grau ao $\mathrm{P}$ resina e à macroporosidade, enquanto os pontos pertencentes à cana encontram-se mais relacionados ao $\mathrm{H}+\mathrm{Al}, \mathrm{Al}, \mathrm{m} \%$ e $\mathrm{Fe}$, e em menor grau à SB.

Devido à mata nativa ser um ecossistema natural e possuir teor de M.O mais elevado, tendo o solo maior proteção da cobertura vegetal, evita-se, assim, a rápida lixiviação dos nutrientes. Em solos tropicais, altamente intemperizados ou não, deve-se ressaltar a importância da M.O para a manutenção da CTC do solo, principalmente em superfície (SANCHES et al., 1999). A M.O tem influência direta sobre a CTC do solo. Os valores de macroporos foram menores no solo cultivado em comparação com os do solo sob mata nativa. Resultados similares, em solo cultivado com canade-açúcar, foram obtidos por Silva e Ribeiro (1992). A drástica redução da macroporosidade nos solos cultivados decorre do aumento da compactação do solo, que é evidenciada pelo aumento da densidade do solo (BORGES; KIEHL; SOUZA, 1999; KAY; ANGERS, 1999). A menor influência de $\mathrm{P}$ em solos naturais já era esperada, devido a não aplicação de fertilizantes fosfatados que, em geral, quando aplicados em áreas cultivadas, resulta no aumento de $\mathrm{P}$ disponível. Na cana, a maior influência de $\mathrm{H}+\mathrm{Al}, \mathrm{Al}$ e $\mathrm{m} \%$ e menor na $\mathrm{SB}$ é devido à extração de nutrientes pela cultura, principalmente quando se encontra no final de mais um ciclo de cerca de 4 a 5 cortes (colheitas). As extrações de nutrientes e perdas por lixiviação são responsáveis pela maior acidificação do solo.

Essa separação dos pontos da mata com a área cultivada com cana salienta o fato de que o cultivo de cana-de-açúcar deve produzir uma modificação acentuada no solo, fazendo com que o mesmo se torne diferente do solo originalmente coberto por floresta latifoliada tropical. As diferenças são devidas às variações de fertilidade natural e melhores condições físicas do solo da mata e aquelas decorrentes de diferentes níveis de adubação da cana.

\section{CONCLUSÕES}

Conclui-se que:

- As matrizes de mata e de cana-de-açúcar se mostraram muito diferentes em relação às características do solo, o que é devido ao tipo de manejo adotado na área com cana.

- A variação dos atributos do solo na vegetação nativa é muito menor quando se compara com solos de usos agrícolas, e por isso a vegetação nativa é um referencial para avaliação de solos incorporados aos sistemas agrícolas. Nessa comparação, podem-se observar as alterações de atributos do solo após a utilização agrícola, verificando, assim, maior sustentabilidade da mata.

- As alterações nas condições químicas e físicas do solo, causada pelo cultivo agrícola da área de cana, revelou a existência de um significativo gradiente positivo entre as distâncias da mata para o interior da área cultivada com cana.

- Os efeitos observados no solo cultivado com cana-de-açúcar foram mais nítidos e acentuados nos primeiros 20 metros de distância da mata, o que provavelmente se deve ao fato de eles estarem próximos da vegetação nativa, apresentando melhores condições da qualidade do solo.

\section{REFERÊNCIAS}

ANDREOLI, C.; SOUZA, S. P. Cana-de-açúcar: A melhor alternativa para conversão da energia solar e fóssil em etanol. Economia \& Energia, v.2, n.59, p. 27-33, 2006. 
BORGES, A.L.; KIEHL, J.C.; SOUZA, L.S. Alteração de propriedades físicas e atividade microbiana de um latossolo amarelo álico após o cultivo com fruteiras perenes e mandioca. Revista Brasileira de Ciência do Solo,v. 23. p.1019-1025, 1999.

EMPRESA BRASILEIRA DE PESQUISA AGROPECUÁRIA (Embrapa). Centro Nacional de Pesquisa de Solos. Manual de métodos de análise de solos. 2. ed. Rio de Janeiro: Embrapa, 1997.

IBGE - Instituto Brasileiro de Geografia e Estatística. Produção agrícola municipal. Disponível em: <http://www.ibge.gov.br>. Acesso em: 15 nov 2009.

KAY, B.D.; ANGERS, D.A. Soil structure. In: A. SUMNER, M.E., ed. Handbook of Soil Science. Boca Raton, CRC Press, 1999. p.229-276.

MAGALHÃES, P. G. 30 anos de Proálcool no centro de debate. Jornal da Unicamp, n. 309, p. 11, 2005.

MARCHIORI JUNIOR, M.; MELO, W.J. Alterações na matéria orgânica e na biomassa microbiana em solo de mata natural submetido a diferentes manejos. Pesquisa Agropecuária Brasileira, Brasília, v.35, n.6, p.1177-1182, 2000.

SANCHES, A.C.; SILVA, A.P.; TORMENA, C.A.; RIGOLIN A.T. Impacto do cultivo de citros em propriedades químicas, densidade do solo e atividade microbiana de um Podzólico VermelhoAmarelo. Revista Brasileira de Ciência do Solo, v.23, p.91-99, 1999.

SILVA, M.L; VALVERDE, S. R; PASSOS, C. A. M; COUTO, L. Viabilidade do reflorestamento do eucalipto consorciado com a cultura do feijoeiro um estudo de caso. Revista Árvore, Viçosa, v.21, n.4, p.527-535, 1997.

SILVA, M.S.L.; RIBEIRO, M.R. Influência do cultivo contínuo da cana-de-açúcar em propriedades morfológicas e físicas de solos argilosos de tabuleiro no estado de Alagoas. Revista Brasileira de Ciência do Solo, v.16, p.397-402, 1992. 